\title{
Dynamic Modeling of a Refrigeration System with an Internal Heat Exchanger and Dual Evaporators through Exergoeconomic Analysis
}

\author{
M. Abid ${ }^{\# 1}$, A. Hepbasli ${ }^{2}$, Khalid Saeed ${ }^{\# 3}$ \\ ${ }^{1}$ Basic Engineering Department, College of Engineering, University of Dammam, Dammam, Kingdom of Saudi \\ Arabia \\ ${ }^{2}$ Department of Energy Systems Engineering, Faculty of Engineering, Yasar University, Bornova,35100 Izmir, \\ Turkey \\ ${ }^{3}$ Department of Mechanical Engineering, College of Engineering, King Saud University ,Riyadh, Kingdom of \\ Saudi Arabia. \\ abid.528633@gmail.com, arif.hepbasli@yasar.edu.tr, khalid.uetp@gmail.com
}

\begin{abstract}
In this study exergy and exergoeconomic analyses of a refrigeration system with two evaporators and an internal heat exchanger were performed. The analysis of the whole system included various thermodynamics parameters such as sustainability index, exergetic improvement potential, ratio of the thermodynamic losses(energetic and exergetic losses) to the capital cost, relative irreversibility for each component of the system. Furthermore, the efficiencies for each component were analyzed using two different approaches, one was the net rational efficiency basis and another one was the product/fuel basis. The whole system efficiency on the net rational basis was determined to be $7.24 \%$ and on the product/fuel basis it was obtained to be $\mathbf{4 3 . 9 2 \%}$. The system has a huge capacity for improvement. The greatest Irreversibility occurs in the compressor with a value of $0.29 \mathrm{~kW}$ and the efficiency values for the compressor using both the approaches were found to be $16.9 \%$ and $21.57 \%$, respectively.
\end{abstract}

Keywords: Economic analysis, Energy, Exergy analysis, Heat exchanger, Refrigeration system.

\section{INTRODUCTION}

Refrigeration engineering has a lot of applications in various types of machinery and plant construction and many other areas. The commonly used refrigerating machine is the compression refrigerating machine, which is based on the compression cycle of the refrigerant. The energy analysis is a basic method for any system and process investigation. Exergy analysis, which is based on second law of thermodynamics, provides more in depth knowledge of irreversibility's in the system. It is also a powerful tool in designing, optimization, and performance evaluation of energy systems while it helps in determining the maximum performance of the systems and key points of exergy destruction. Exergy analysis is very important for each system to get the information about the actual losses in the system and also for optimization of the system. For these reasons, the modern approach to a process analysis uses the exergy analysis, which provides a more realistic view of the process. Identifying the main sites of exergy destruction gives the direction for potential improvements. An important objective of exergy analysis for systems that consume power such as refrigeration is finding the minimum power required for a certain desired result[1]. There have been several studies on the exergy analysis of refrigeration and heat pump systems[2-7].

Dincer $^{7}$ reported the relationship between energy and exergy, exergy and the environment, energy and sustainable development, and energy policy making details. In case of large systems component wise, exergy analysis is performed. Potential improvement in the system can be obtained after calculating exergy destruction for each component. There have been several studies on the exergy analysis of refrigeration and heat pump systems. Torres-Reyes et al.[8] studied a solar assisted heat pump experimentally, and optimized the system using exergy analysis. Bayrakci and Ozgur[9] conducted the exergy analysis of a vapor compression refrigeration system with an internal heat exchanger. In their study a comparison of energetic and exergetic performance of a vapor compression refrigeration system using pure hydrocarbon (HC) refrigerants was performed. The engineering equation solver software was used for the analysis purpose. Kabul et al.[10] studied the energy and exergy analysis for vapor compression system with refrigerant R600a at specified operating conditions. Energy and exergy fluxes were obtained, and irreversibility rates were calculated for each component of the system. It was observed that the compressor had the highest irreversibility rate, and the heat exchanger had the lowest rate. Also from their result, it was found that condenser and evaporator temperatures had strong effects on energetic and exergetic performances of the system such as coefficient of performance, 
efficiency ratio, exergetic efficiency, and irreversibility rate. Chandrasekhran[11] also performed exergy analysis of a vapor compression refrigeration system using two different refrigerants (R12 and R134a)and concluded that COP increased when the evaporator temperature increased for both refrigerants. COP of R134a was slightly higher at lower temperature while COP of R12 was higher at high evaporator temperature. Variation of exergetic efficiency of both refrigerants was found to be similar to that of COP. Stegou-Sagia and Paignigiannis[12] performed exergy analysis to describe irreversibilities in one stage refrigerating process for vapor compression cycle with refrigerant mixtures R-404A, R-410A, R-410B and R-507. Emphasis was given to parameters influencing the losses in the cycle. Also detailed information on the variation of cycle's exergy efficiency with evaporating and condensing temperatures was reported. Alexis[13] applied exergy analysis method to a steam-ejector refrigeration system. It was concluded that a better quality of the ejector had more effect on the system performance compared to the quality of other components, because the ejector at first and the condenser at second had the greater exergy loss of the system. The methodology of the EXCEM method was developed earlier by Rosen[14]. EXCEM approach was applied to ground source heat pumps by Ozgener et al.[15] Similarly, Hepbasli[16] made exergy and exergoeconomic analyses of household refrigerators based on the measured values at varying reference state temperatures.

In our study, energy, exergy and exergoeconomic analysis of refrigeration system have been performed with an internal heat exchanger and dual evaporators. The refrigeration system with an internal heat exchanger is considered in the analysis, having the capability to control and maintain the temperature precisely in each section. An evaporation pressure controller is used to get the two different temperatures inside the freezer and cooler chamber. As mentioned above, there are many studies performed on the exergy analysis of refrigeration systems and very few studies on the exergoeconomic analysis of refrigeration systems. The system considered in this analysis is different (having an internal heat exchanger, dual evaporators and evaporation pressure controller), and no studies have been reported in the open literature(to the best of the authors' knowledge) on the exergy and exergoeconomic analysis (EXCEM method) of such system. Therefore this study will provide an insight into these types of systems for possible improvements.

\section{DESCRIPTION OF THE SYSTEM}

The refrigeration system analyzed was a fully functional compression refrigerating machine with a freezer and cooler chamber kept at two different temperatures. Evaporation pressure controller is used to keep the two chambers at different temperatures. Two evaporators are mainly used, one evaporator is located in a freezer chamber, equipped with defrosting heating, which acts as a cooling load for the system. The cooling load capacity is $150 \mathrm{~W}$. A second evaporator is integrated into a normal refrigeration chamber, and one calls it cooling chamber or cooler. Also the system has an internal heat exchanger through which the refrigerant super cooling can be achieved before it goes to the expansion valve and rotameter. The compressor takes in cold refrigerant vapor from the low pressure area after evaporation in the two chambers. After it has been received inside the compressor, the vapor is compressed almost isentropically. This enhances the temperature of the vapor to the final compression temperature. The superheated refrigerant vapor then goes to the condenser, where it condenses isobarically and cools down. Forced convection is used in the condenser to give off the resulting heat more effectively to the environment.

After condensation, the refrigerant goes to the receiver. From here, it goes to the rotameter either through an internal heat exchanger. Valves are fitted. The option of connecting the heat exchanger depends on the position of the corresponding valves. From the rotameter, the refrigerant flows first through the filter dryer. There are two solenoid valves, which control the flow to both the expansion valves. A diverter valve acts as a controller whether one or the other coil or both, are active at any given time by routing the refrigerant accordingly. The fraction of the two partial flows depends upon the opening of the subsequent thermostatic expansion valves. In the expansion valves the refrigerant expands and returns to a lower pressure level shown in Fig. $1(\mathrm{a}, \mathrm{b})$ as points 5 and 6 . Fig. $1 \mathrm{~b}$ represents the logarithmic pressure verses enthalpy diagram for the considered system. The pressure level in the standard evaporator 2 can also be adjusted using an evaporation pressure controller. After the expansion valves, the refrigerant flows through evaporators and absorbs heat energy in the two evaporators, which reduce the temperature in the two chambers. The refrigerant is slightly superheated when it exits the evaporators. After the refrigerant have passed through both the evaporators, the two refrigerant flows join together again. The refrigerant vapor is then fed back to the compressor via the internal heat exchanger at point 10 . The temperature at twelve(12) different points are measured with the help of thermocouples, as shown in Fig. 1a. Similarly the pressures are monitored before and after the expansion valves in both lines, and also before entry to the compressor and after exit from the compressor through pressure sensor. The power consumed by the compressor is measured through the power meter, which works in the range of $0-1000 \mathrm{~W}$. 


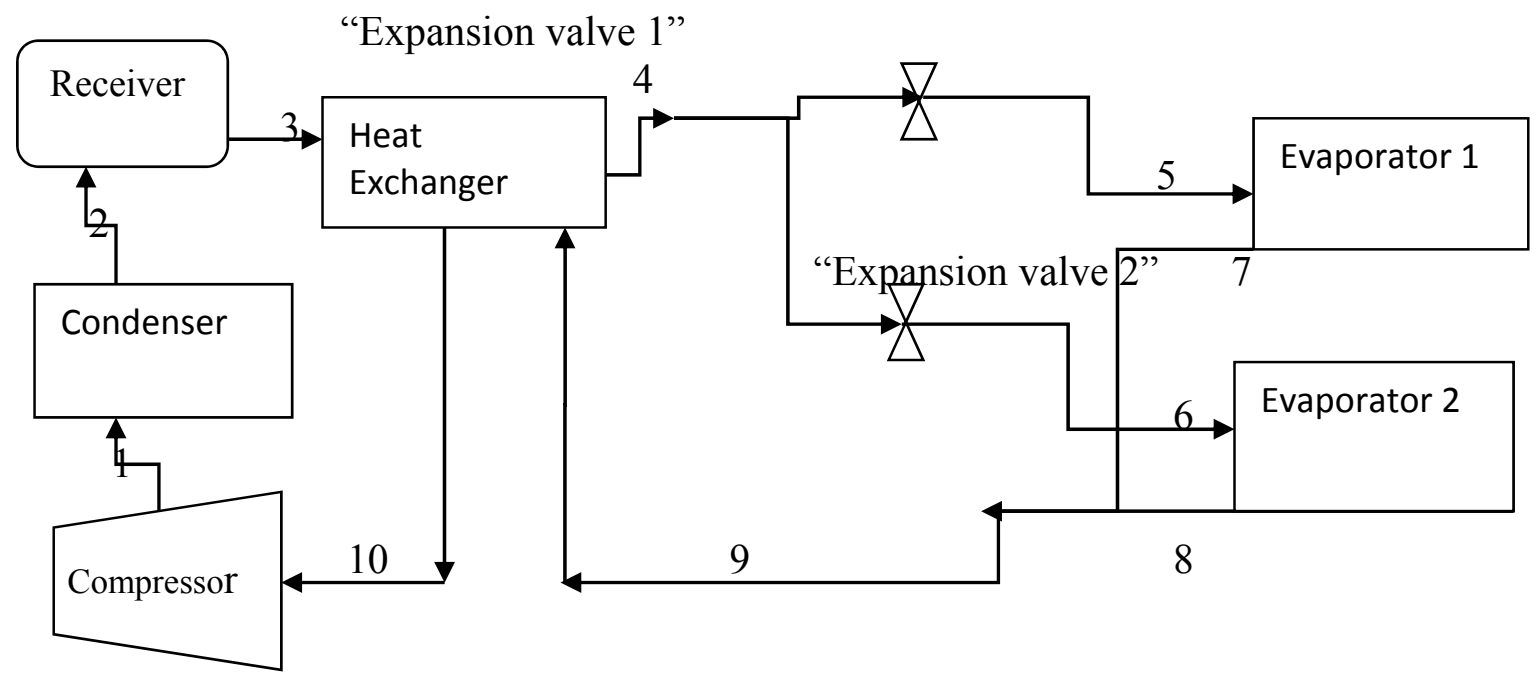

(a)

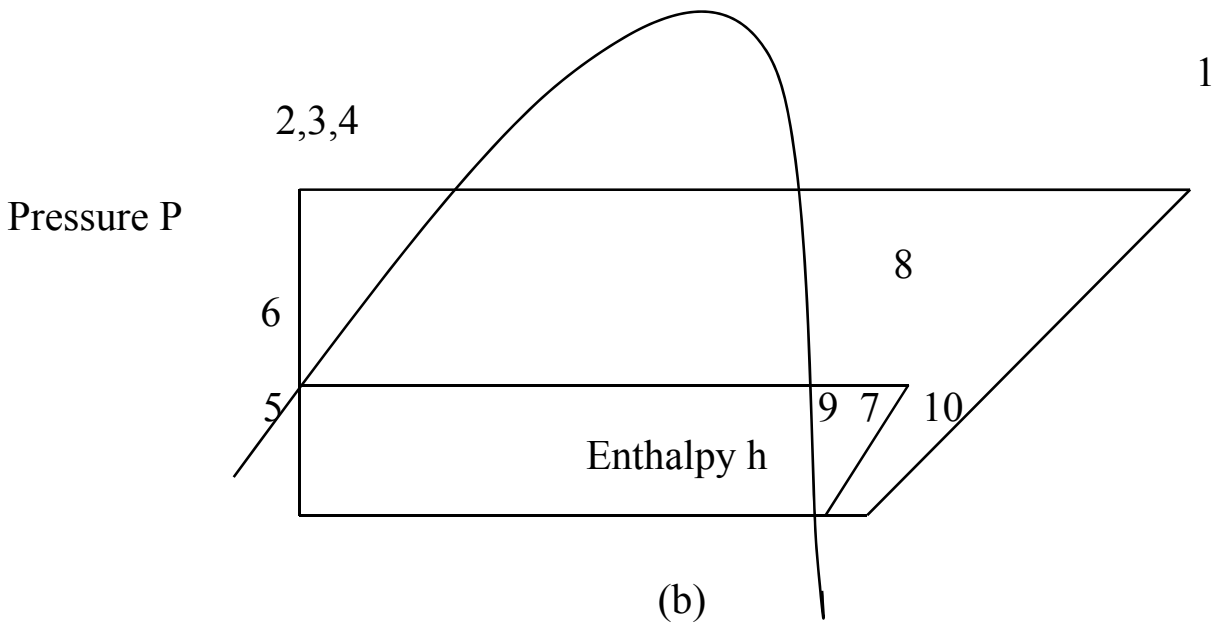

Fig. 1. a) System Circuit Diagra; b) Logarithmic Pressure(P) vs. enthalpy(h) diagram for the system considered.

\section{ANALYSIS}

Mathematical formulation is used for the vapor compression refrigeration cycle with dual evaporators and an internal heat exchanger for the exergy and Exergoeconomic analyses. The system mainly consists of eight components: evaporator 1, evaporator 2, compressor, internal heat exchanger condenser, receiver, expansion valvel and expansion valve 2. External energy (electrical power) is supplied to the compressor and heat is added to the system in the evaporator as a cooling load, whereas in the condenser the heat rejection takes place from the system. All the components have different exergy losses in various components of the system. The reference state temperature and pressure are denoted by Temperature $\mathrm{T}_{0}$ and Pressure $\mathrm{P}_{0}$; respectively. The exergy and exergoeconmic analyses of the refrigerators have been performed based on the experimental data.

\section{A. Energy and exergy analyses}

Energy and exergy rate balance equations for a component or a system can be written by the following equations given by Rosen and Dincer [17].

$$
\begin{aligned}
& \dot{E}_{\text {in }}-\dot{E}_{\text {out }}=\dot{L}_{\text {en }} \\
& \dot{E} x_{\text {in }}-\dot{E} x_{\text {out }}=\dot{L}_{e x}
\end{aligned}
$$


whereas $\dot{E}_{\text {in }}$ is energy rate input, $\dot{E}_{\text {out }}$ energy rate output, and $\dot{L}_{e n}$ is the energy losses rate. $\dot{E} X_{\text {in }}$ is exergy rate input and $\dot{E} x_{\text {out }}$ is the exergy rate output, while $\dot{L}_{e x}$ denotes the exergy destruction rate.

The cost balance equation can be written as follows

$$
K_{\text {in }}+K_{\text {gen }}-K_{\text {out }}=K_{\text {ac }}
$$

where $\mathrm{K}$ is capital cost and the subscripts in, out, gen denotes input, output and generation respectively. The exergy rate at any point is given by the following relation:

$$
\dot{E} x=\dot{m} \psi
$$

with specific exergy $(\psi)$ given by the following relation:

$$
\psi=\left(h-h_{0}\right)-T_{0}\left(s-s_{0}\right)
$$

Exergy destructions and exergy efficiency relations obtained from exergy balances equation for each of the refrigerator components shown in Fig. 1a can be obtained as follows:

\section{1) Evaporator 1}

The mass flow rate balance equation and the fraction of mass flow rate through an "evaporator 1"are given by the following relation.

$$
\dot{m}_{i}=\dot{m}_{5}=\dot{m}_{7}=\dot{m}_{\text {evap } 1} \quad \dot{m}_{5}=\dot{m}_{\text {freezer }}=\left(\frac{\dot{Q}_{\text {evap } 1}}{h_{7}-h_{5}}\right)
$$

whereas the $\dot{Q}_{\text {evap1 }} \quad$ can be found through the temperature difference between the freezer chamber and reference state temperature multiplied by coefficient of heat transfer $\mathrm{k}$, and is given by the following relationship.

$$
\dot{Q}_{\text {evap } 1}=k\left(T_{0}-T_{\text {freezer }}\right)=\dot{m}_{\text {evap } 1}\left(h_{7}-h_{5}\right)
$$

The exergy destruction rate through the "evaporator 1 " can be written as follows:

$$
\dot{E} x_{\text {destruction,evap } 1}=\dot{m}_{\text {evap } 1}\left(\psi_{5}-\psi_{7}\right)-\dot{E} x_{\text {heat }, \text { evap } 1}
$$

whereas $\dot{E} X_{\text {heat }, \text { evap } 1}$ can be written by the following relation

$$
\dot{E} x_{\text {heat }, \text { evap } 1}=\dot{Q}_{\text {evap } 1}\left(\frac{T_{0}-T_{\text {evap } 1}}{T_{\text {evap } 1}}\right)
$$

while the $\dot{Q}_{\text {evap } 1} \quad$ value can be calculated by Equation (7) and $T_{\text {evap } 1}$ is the temperature inside the freezer chamber, which is also measured through a thermocouple inside the chamber.

The exergy efficiency for the "evaporator 1 " $\left(\varepsilon_{\text {evap } 1}\right)$ is given by the following relation:

$$
\varepsilon_{\text {evap } 1}=\frac{\dot{E} x_{\text {heat }, \text { evap } 1}}{\dot{E} x_{5}-\dot{E} x_{7}}
$$

2) Evaporator 2:The mass flow rate balance equation through the "evaporator 2" can be written as follows:

$$
\dot{m}_{6}=\dot{m}_{8}=\dot{m}_{\text {cooler }}
$$

whereas the mass flow rate in the evaporator can be found by the following relation:

$$
\dot{m}_{6}=\dot{m}_{\text {evap } 2}=\left(\frac{\dot{Q}_{\text {evap } 2}}{h_{8}-h_{6}}\right)
$$

and $\quad \dot{Q}_{\text {evap } 2} \quad$ can be given by the following relationship:

$$
\dot{Q}_{\text {evap } 2}=k\left(T_{0}-T_{\text {cooler }}\right)=\dot{m}_{\text {evap } 2}\left(h_{8}-h_{6}\right)
$$


whereas $\mathrm{k}$ is the heat transfer coefficient.

The exergy destruction rate for the "evaporator 2" is given by the following relationship,

$$
\dot{E} X_{\text {destruction,evap } 2}=\dot{m}_{\text {evap } 2}\left(\psi_{6}-\psi_{8}\right)-\dot{E} x_{\text {heat,evap } 2}
$$

with $\dot{E} x_{\text {heat,evap } 2}$ is given as follows:

$$
\dot{E} X_{\text {heat }, \text { evap } 2}=\dot{Q}_{\text {evap } 1}\left(\frac{T_{0}-T_{\text {evap } 2}}{T_{\text {evap } 2}}\right)
$$

where $T_{\text {freezer }}$ is the temperature inside the freezer chamber.

The exergy efficiency $\left(\varepsilon_{\text {evap } 2}\right)$ is given by the following relation:

$$
\varepsilon_{\text {evap } 2}=\frac{\dot{E} x_{\text {heat }, \text { evap } 2}}{\dot{E} x_{6}-\dot{E} x_{8}}
$$

3) Compressor: The mass flow rate balance equation for the compressor can be written as follows:

$$
\dot{m}_{t}=\dot{m}_{10}=\dot{m}_{1}
$$

and the work performed by the compressor can be written as in terms of enthalpy,

$$
\dot{W}_{\text {comp }}=\dot{m}_{t}\left(h_{1}-h_{10}\right)
$$

where $h_{1}$ is the refrigerant enthalpy after the real compression process. This enthalpy can be obtained from isentropic enthalpy as follows:

$$
h_{1}=\left(\frac{h_{1, s}-h_{10}}{\eta_{\text {comp }}}\right)+h_{10}
$$

The mechanical and electrical combined efficiency for the compressor can be written as follows:

$$
\eta_{\text {comp }, \text { mech,elect }}=\left(\frac{\dot{W}_{\text {comp }}}{\dot{W}_{\text {comp }, \text { elect }}}\right)
$$

The exergy destruction rate in the compressor is given by

$$
\dot{E} x_{\text {destruction, comp }}=\dot{m}_{t}\left(\psi_{10}-\psi_{1}\right)+\dot{W}_{\text {comp, elect }}
$$

The heat supplied to the environment is neglected. While the mechanical and electrical losses can be calculated from

$$
\dot{E} x_{\text {dest,comp,mech,elect }}=\dot{W}_{\text {comp,elect }}\left(1-\eta_{\text {comp, mech,elect }}\right)
$$

whereas the $\eta_{\text {comp,mech,elect }}$ can be found by using Equation (20).

The internal Irreversibility due to fluid friction can be calculated using

$$
\dot{E} x_{\text {dest,comp,int }}=\dot{E}_{\text {dest,comp }}-\dot{E} x_{\text {dest,comp, mech,elect }}
$$


Now the exergy efficiency of compressor $\left(\varepsilon_{\text {comp }}\right)$ can be written as follows:

4) Condenser:

$$
\varepsilon_{\text {comp }}=\frac{\dot{E} x_{1}-\dot{E} x_{10}}{\dot{W}_{\text {comp }, \text { elect }}}=\frac{\dot{m}_{t}\left(\psi_{1}-\psi_{10}\right)}{\dot{W}_{\text {comp }, \text { elect }}}
$$

The mass flow rate balance equation for the condenser is as follows:

$$
\dot{m}_{t}=\dot{m}_{2}=\dot{m}_{1}
$$

The heat lost rate in the condenser can be found by the relation;

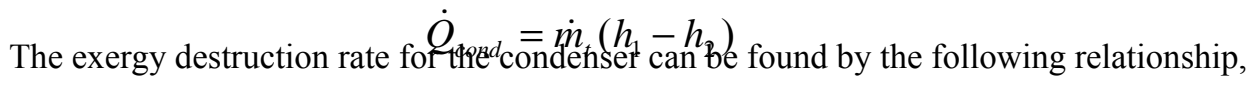

and the exergy efficiency relation is given by

$$
\dot{E} x_{\text {dest,cond }}=\dot{m}_{t}\left(\psi_{1}-\psi_{2}\right)-\dot{Q}_{\text {cond }}\left(1-\frac{T_{0}}{T_{\text {cond }}}\right)
$$

$$
\varepsilon_{\text {cond }}=\frac{\dot{E} x_{2}}{\dot{E} x_{1}}=\frac{\psi_{2}}{\psi_{1}}
$$

5) Receiver: The mass flow rate balance equation for the receiver is given as follows:

$$
\dot{m}_{t}=\dot{m}_{3}=\dot{m}_{2}
$$

With exergy destruction rate

and the exergy efficiency

$$
\dot{E} X_{\text {dest }, \text { rec }}=\dot{m}_{t}\left(\psi_{2}-\psi_{3}\right)
$$

$$
\varepsilon_{\text {rec }}=\frac{\dot{E} x_{3}}{\dot{E} x_{2}}
$$

6) Internal heat exchanger: The mass flow rate balance equation for the internal heat exchanger is given as follows:

$$
\dot{m}_{t}=\dot{m}_{3}=\dot{m}_{4}=\dot{m}_{9}=\dot{m}_{10}
$$

The heat loss by between points 3 and 4 is equal to the heat gain between points 9 and 10 , and is given as follows;

$$
\dot{Q}_{H . E}=\dot{m}_{t}\left(h_{3}-h_{4}\right)=\dot{m}_{t}\left(h_{10}-h_{9}\right)
$$

The exergy destruction rate for the heat exchanger is given by

$$
\dot{E} x_{\text {dest }, H . E}=\dot{m}_{t}\left(\left(\psi_{3}-\psi_{4}\right)-\left(\psi_{10}-\psi_{9}\right)\right)
$$

with exergy efficiency

$$
\varepsilon_{H . E}=\frac{\dot{E} x_{10}-\dot{E} x_{9}}{\dot{E} x_{3}-\dot{E} x_{4}}=\frac{\dot{m}_{t}\left(\psi_{10}-\psi_{9}\right)}{\dot{m}_{t}\left(\psi_{3}-\psi_{4}\right)}
$$


7) Expansion valve 1:The mass flow rate through the expansion valve 1 is given by $\dot{m}_{5}$ as follows:

whereas

$$
\dot{m}_{5}=\dot{m}_{\text {freezer }}=\left(\frac{\dot{Q}_{\text {freezer }}}{h_{7}-h_{5}}\right)
$$

The exergy destruction rate for expansion valve 1 can be found by

$$
\dot{E} X_{\text {dest }, \text { expan } 1}=\left(\dot{m}_{t} \psi_{4}-\dot{m}_{5} \psi_{5}\right)
$$

and exergy efficiency is given as follows:

$$
\varepsilon_{\text {exp an } 1}=\frac{\dot{E} x_{5}}{\dot{E} x_{4}}=\frac{\dot{m}_{5} \psi_{5}}{\dot{m}_{t} \psi_{4}}
$$

8 ) Expansion valve 2: The mass flow rate balance for expansion valve2 is given by the following relationship:

and $\quad \dot{Q}_{\text {evap 2 }} \quad$ is given by equation (13) above;

The exergy destruction rate is given as follows:

$$
\dot{E} X_{\text {dest, expan } 2}=\dot{m}_{t} \psi_{4}-\dot{m}_{6} \psi_{6}
$$

and the exergy efficiency by the following relationship:

$$
\varepsilon_{\text {exp an } 2}=\frac{\dot{E} x_{6}}{\dot{E} X_{4}}=\frac{\dot{m}_{6} \psi_{6}}{\dot{m}_{t} \psi_{4}}
$$

9) Whole system exergy destruction, COP and exergy efficiency: The total exergy destruction rate can be obtained by adding all the exergy destruction rate by each component listed above and is given as follows;

$$
\dot{E} x_{\text {dest,total }}=\dot{E} x_{\text {dest,evap1 }}+\dot{E} x_{\text {dest,evap } 2}+\dot{E} x_{\text {dest,comp }}+\dot{E} x_{\text {dest,cond }}+\dot{E} x_{\text {dest, rec }}+\dot{E} x_{\text {dest,expan1 }}+\dot{E} x_{\text {dest,expan } 1}
$$

The relative irreversibility(which determines the percentage of the exergy destruction contributed by each term ) for each component can be calculated using the following relationship;

$$
\text { Relative irreversibility }(R I)=\frac{\dot{E} x_{\text {dest }, i}}{\dot{E} x_{\text {dest,total }}}
$$

The COP for the system can be calculated by the following relation:

$$
\text { COP }=\frac{\dot{Q}_{\text {total }}}{\dot{W}_{\text {comp }, \text { elect }}} \frac{\dot{Q}_{\text {cooler }}+\dot{Q}_{\text {freezer }}}{\dot{W}_{\text {comp }, \text { elect }}}
$$

and the exergy efficiency on the net rational efficiency basis can be written as follows:

$$
\varepsilon_{\text {system }}=\frac{\dot{E} x_{\text {evap } 1}+\dot{E} x_{\text {evap } 2}}{\dot{W}_{\text {comp }, \text { elec }}}=\frac{\left(\dot{E} x_{5}-\dot{E} x_{7}\right)+\left(\dot{E} x_{6}-\dot{E} x_{8}\right)}{\dot{W}_{\text {comp }, \text { elect }}}
$$


On the product/fuel basis for the whole system

\section{B. Exergoeconomic analysis}

$$
\varepsilon_{\text {system }}=\frac{\dot{P}}{\dot{F}}
$$

An instructive parameter is the ratio $R$ of thermodynamic loss $L$ to capital cost $K$ is useful in the exergoeconomic analysis of any energy system. The value of $R$ generally depends on whether it is based on the ratio of energy loss rate to capital cost, in that case it is denoted $\dot{R}_{e n}$ or the ratio of exergy loss rate to the cost, in which case it is denoted by $\dot{R}_{e x}$ reported by Rosen and Dincer[17]. These two terms are given by the following equations;

$$
\begin{gathered}
\dot{R}_{e n}=\frac{\dot{L}_{e n}}{K_{g e n}} \\
\dot{R}_{e x}=\frac{\dot{L}_{e x}}{K_{g e n}}
\end{gathered}
$$

\section{Sustainability assessment}

Sustainability assessment requires the resources to be used effectively, and it is performed with sustainability index (SI) method, which is related to exergy efficiency. Exergy methods are essential in improving efficiency that allows society to maximize the benefits it derives from its resources while minimizing the negative impacts, such as environmental damage as reported by Rosen et al.[18]. Thus, the SI method based on exergy efficiency is a useful tool to obtain sustainability assessment by the following relationship.

$$
S I=\frac{1}{1-\varepsilon}
$$

\section{Exergetic improvement potential}

The maximum improvement in the exergy efficiency for a process or system is obviously achieved when the exergy loss or irreversibility rate $\left(\dot{E} X_{\text {in }}-\dot{E} X_{\text {out }}\right)$ is reduced. Consequently, as suggested by Van Gool.[19], it is useful to employ the concept of an exergetic "improvement potential" when analyzing different processes or sectors of the economy. This improvement potential rate, denoted by $I \dot{P}$ is given by the following relationship:

$$
\dot{I P}=(1-\varepsilon) *\left(\dot{E} x_{\text {in }}-\dot{E} x_{\text {out }}\right)
$$

\section{E. Uncertainty analysis}

In these experimental results, there may be some inaccuracies in measuring the primary data. It needs a description of such inaccuracies. It is known that an appropriate idea for expressing inaccuracies is an "uncertainty" and the actual value should be provided by an "uncertainty analysis". It is well known that errors and uncertainties in any experiments can arise from instrument selection, instrument condition, instrument calibration, environmental conditions, observation and reading and test planning. Uncertainty analysis is needed to prove the accuracy of the experiments. In the present study, the temperatures, pressure, velocity, flow rates and electrical powers are measured with appropriate instruments as explained in the system Description Section.

The total uncertainty of any measured parameter may be calculated as given by Holman [20] as follows:

$$
u_{T}=\left[u_{\text {sensor }}^{2}+u_{\text {Dac }}^{2}+u_{\text {calibration }}^{2}\right]^{2}
$$

where $u_{T}$ is the total uncertainty in any measured parameter, $u_{\text {sensor }}$ is the uncertainty in the sensor reading, $u_{D a c}$ is the uncertainty associated with the data acquisition system and $u_{\text {calibration }}$ is the uncertainty in the calibration procedure. 
The uncertainty arising in calculating any result $(R)$ due to several independent variables uncertainties $\left(x_{1}, x_{2}, x_{3}, \ldots \ldots \ldots . . . X_{m}\right)$ is given by Coleman and Steele Steele[21], and can be expressed as follows:

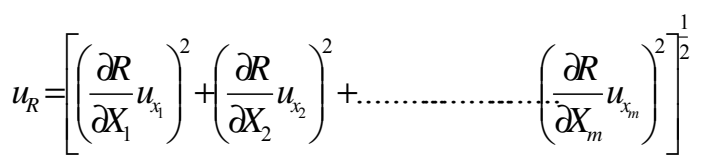

In our study, the primary measured parameters are temperature, pressure, flow rate and electrical power, which are used for further calculation of the exergy, and exergoeconomic analysis of the system. These uncertainties for the measured and calculated values must be taken into account in experimental studies to make it more meaningful.

\section{RESULTS AND DISCUSSION}

The following assumptions were made during the analysis and calculation to get the final results for the system performance.

$>$ Steady-state operation in all components of the system with negligible potential and kinetic energy effects.

Pressure losses through the piping system have been neglected.

$>$ Heat gains and heat losses from or to the system are not considered.

D Heat gains and heat losses from or to the internal heat exchanger have been neglected.

$>$ The power consumption for the condenser and both the evaporators have been not considered in the analysis.

$>$ The freezer chamber is maintained at a temperature of $-9.1{ }^{\circ} \mathrm{C}$ and the cooler chamber is maintained at $4.4^{\circ} \mathrm{C}$.

> The system was analyzed at a reference state temperature of $25^{\circ} \mathrm{C}$, pressure (P) is $101 \mathrm{kPa}$, enthalpy (h) is $424.3 \mathrm{kJkg}^{-1} \mathrm{~K}^{-1}$ and entropy is equal to $1.9 \mathrm{kJkg}^{-1}$.

$>$ Total mass flow rate is equal to $0.00132 \mathrm{kgs}^{-1}$.

$>$ The coefficient of heat transfer for the both the evaporators were taken to be equal with a value of $3.65 \mathrm{WK}^{-1}$. This value is based on the experimental results and is used to calculate the mass flow rate in the two evaporators.

$>$ The total uncertainty in the flow rate was assumed to be $\pm 1.45 \%$.

$>$ The average uncertainty associated with the measurement of electrical power was assumed to be \pm $0.7 \%$.

The properties of the refrigerant R-134, the values for temperature, pressure, enthalpy, entropy, and mass flow rates are given in Table 1. The thermodynamic properties of the refrigerants studied were found using the cycle pad software package. Also the specific exergy, exergy rate, and energy rate values at every state point are shown in Table 1 according to the circuit diagram shown in Fig. 1a. exergy destruction, exergetic fuel and product, two different exergy efficiencies values are presented in Table 2, using the relation for each component and the overall system. The whole system exergy efficiency on net rational basis and product/fuel basis are given by Equations (45) and (46), respectively. Similarly, the exergy efficiency for evaporator 1, evaporator 2, the compressor, the internal heat exchanger, the condenser, the receiver, expansion TABLE 1

Energetic and exergetic values for the system at different state points

\begin{tabular}{|c|c|c|c|c|c|c|c|c|c|}
\hline $\begin{array}{l}\text { State } \\
\text { point }\end{array}$ & $\begin{array}{l}\text { Component } \\
\text { with inlet and } \\
\text { outlet values }\end{array}$ & $\begin{array}{l}\text { Temperature, } T \\
\left({ }^{\circ} \mathrm{C}\right)\end{array}$ & $\begin{array}{l}\text { Pressure, } P \\
\text { (bar) }\end{array}$ & $\begin{array}{l}\text { Specific } \\
\text { enthalpy, } \\
\text { h }\left(\mathbf{k J k g}^{-1}\right)\end{array}$ & $\begin{array}{l}\text { Specific } \\
\text { entropy, } \\
\left.\text { s(kJkg }^{-1} K^{-1}\right)\end{array}$ & $\begin{array}{l}\text { Mass flow } \\
\text { rate , } \dot{m} \\
\left(\mathrm{Kgs}^{-1}\right)\end{array}$ & $\begin{array}{l}\text { Specific } \\
\text { exergy } \\
\psi_{(\mathbf{k J k g}} \\
\left.{ }^{1}\right)\end{array}$ & $\begin{array}{l}\text { Exergy } \\
\text { rate } \\
\dot{E} x \\
(\mathbf{k W})\end{array}$ & $\begin{array}{l}\text { Energy } \\
\text { rate } \dot{E} \\
(\mathrm{~kW})\end{array}$ \\
\hline 1 & $\begin{array}{l}\text { T1, Outlet } \\
\text { Compressor }\end{array}$ & 96.5 & 14.81 & 474.71 & 1.86 & 0.00132 & 62.33 & 0.082 & 0.62 \\
\hline 2 & $\begin{array}{l}\text { T2, Outlet } \\
\text { Condenser }\end{array}$ & 28.83 & 14.81 & 239.6 & 1.12 & 0.00132 & 47.74 & 0.063 & 0.31 \\
\hline 3 & $\begin{array}{l}\text { T3, Outlet } \\
\text { Refrigeration } \\
\text { Receiver }\end{array}$ & 28.31 & 14.81 & 239.41 & 1.12 & 0.00132 & 47.55 & 0.062 & 0.31 \\
\hline
\end{tabular}




\begin{tabular}{|c|c|c|c|c|c|c|c|c|c|}
\hline 4 & $\begin{array}{l}\text { T4, Outlet Heat } \\
\text { Exchanger }\end{array}$ & 27.3 & 14.81 & 237.96 & 1.12 & 0.00132 & 46.1 & 0.060 & 0.31 \\
\hline 5 & $\begin{array}{l}\text { T5, Outlet } \\
\text { Expansion } \\
\text { Valve } 1\end{array}$ & -14.7 & 1.67 & 237.96 & 1.15 & 0.00085 & 37.16 & 0.031 & 0.20 \\
\hline 6 & $\begin{array}{l}\text { T6, Outlet } \\
\text { Expansion } \\
\text { Valve } 2\end{array}$ & -1.51 & 2.79 & 237.96 & 1.14 & 0.00047 & 40.14 & 0.018 & 0.11 \\
\hline 7 & $\begin{array}{l}\text { T7, Outlet } \\
\text { Evaporator } 1\end{array}$ & -12.71 & 1.67 & 391 & 1.74 & 0.00085 & 14.38 & 0.012 & 0.33 \\
\hline 8 & $\begin{array}{l}\text { T8, Outlet } \\
\text { Evaporator } 2\end{array}$ & 2.94 & 2.79 & 401.4 & 1.74 & 0.00047 & 24.78 & 0.011 & 0.188 \\
\hline 9 & $\begin{array}{l}\text { T9, Inlet Heat } \\
\text { Exchanger }\end{array}$ & -12.5 & 2 & 392.2 & 1.73 & 0.00132 & 18.56 & 0.024 & 0.51 \\
\hline 10 & $\begin{array}{l}\text { T10, Inlet } \\
\text { Compressor }\end{array}$ & -2.27 & 2 & 398.9 & 1.73 & 0.00132 & 18.93 & .025 & 0.52 \\
\hline
\end{tabular}

valve1 and expansion valve 2 are calculated using the respective relations given above in the analysis section. The relative irriversibility, COP value for the system, sustainability assessment values, improvement potential rate values are for each component and the whole system are calculated using Equations (43), (44), (49) and (50),

TABLE 2

Exergy efficiencies, exergy destruction, sustainability index, improvement potential and EXCEM parameters for the each component of the system

\begin{tabular}{|c|c|c|c|c|c|c|c|c|c|c|c|c|}
\hline Component & $\begin{array}{l}\dot{E} x_{d e s t} \\
(k W)\end{array}$ & $\begin{array}{l}\dot{F} \\
(k W)\end{array}$ & $\begin{array}{l}\dot{P} \\
(k W)\end{array}$ & $\begin{array}{l}\mathcal{E}_{1} \\
(\%)\end{array}$ & $\begin{array}{l}\varepsilon_{2} \\
(\%)\end{array}$ & $\begin{array}{l}R I \\
(\%)\end{array}$ & $\begin{array}{l}\text { K } \\
\text { (USD) }\end{array}$ & $\begin{array}{l}\dot{L}_{e n} \\
(\mathbf{k W})\end{array}$ & $\begin{array}{l}\dot{R}_{e n} \\
\left(* 10^{-4}\right) \\
\text { kWUS } \\
\$^{-1}\end{array}$ & $\begin{array}{l}\dot{R}_{e x} \\
\left(* 10^{-4}\right) \\
(\text { kWUS\$ } \\
\text { 1) }\end{array}$ & $S I$ & $\begin{array}{l}I \dot{P} \\
\left(* 10^{-4}\right) \\
(\mathbf{k W})\end{array}$ \\
\hline Evaporator 1 & 0.002 & 0.031 & .029 & 93.54 & 89.47 & 0.52 & 66.6 & 0.13 & 19.5 & 0.3 & 14.28 & 1.4 \\
\hline Evaporator 2 & 0.0014 & 0.018 & 0.0166 & 92.22 & 81 & 0.36 & 53.3 & 0.078 & 14.6 & 0.26 & 12.85 & 1.09 \\
\hline Compressor & 0.29 & 0.38 & 0.082 & & 16.9 & 76.29 & 239.8 & 0.1 & 4.17 & 12.09 & 1.26 & 2274.4 \\
\hline
\end{tabular}




\begin{tabular}{|l|l|l|l|l|l|l|l|l|l|l|l|l|}
\hline Condenser & .0159 & .082 & .0661 & 80.06 & 76.82 & 4.18 & 39.9 & 0.31 & 77.6 & 2.04 & 5 & 0.31 \\
\hline Receiver & .001 & .063 & .062 & 98.41 & 98.41 & 0.26 & 13.3 & 0 & 0 & 0.75 & 50 & 0.2 \\
\hline $\begin{array}{l}\text { Internal Heat } \\
\text { Exchanger }\end{array}$ & .001 & .002 & .001 & 50 & 50 & 0.26 & 13.3 & 0 & 0 & 0.75 & 2 & 5 \\
\hline $\begin{array}{l}\text { Expansion } \\
\text { valve 1 }\end{array}$ & .029 & .06 & .031 & 51.66 & 51.66 & 7.31 & 26.6 & 0 & 0 & 10.9 & 2.04 & 142.1 \\
\hline $\begin{array}{l}\text { Expansion } \\
\text { valve 2 }\end{array}$ & .042 & .06 & .018 & 30 & 30 & 11.05 & 26.6 & 0 & 0 & 15.7 & 1.42 & 294 \\
\hline \begin{tabular}{l} 
Overall System \\
\hline
\end{tabular} & 0.38 & 0.696 & 0.305 & 43.92 & 7.24 & 100 & 479.4 & 0.618 & 12.8 & 7.92 & 1.75 & 2131.04 \\
\end{tabular}

respectively. All the values were calculated based on the reference state temperature and pressure values. The greatest irreversibility rate (exergy destruction rate) occurs in the compressor, followed by the expansion valve 2 , expansion valve 1 , the condenser, evaporator 1 , evaporator 2 , the internal heat exchanger, and the receiver with values of $0.29 \mathrm{~kW}, 0.042 \mathrm{~kW}, 0.029 \mathrm{~kW}, 0.0159 \mathrm{~kW}, 0.002 \mathrm{~kW}, 0.0014 \mathrm{~kW}, 0.001,0.001 \mathrm{~kW}$, respectively as shown in the Table 2 . The parentage contributed by the compressor in the whole system losses is by the compressor with a value of $76.29 \%$, as can be seen from the relative irreversibility value.

The compressor mechanical and electrical efficiency were calculated to be $27.8 \%$ with the help of Equation (21), with an internal destruction of $0.038 \mathrm{~kW}$ using Equation (21), and these values are based on the actual experimental values taken from the system. The power consumption of the compressor is $0.359 \mathrm{~kW}$. The mechanical-electrical losses are due to imperfect electrical, mechanical and isentropic efficiencies, and therefore it is important to pay special attention to the selection of these devices, since components of low performance can considerably reduce the overall system performance. As the compressor power depends on the inlet and outlet pressures, the improvement in heat exchanger can reduce the temperature difference and as a result the power consumption by the compressor will be reduced, bringing the condensing and evaporating temperatures closer together. The average uncertainties arisen from the measurement of temperatures were systematically classified as follows; a) The average uncertainty arisen from the fabrication of thermocouples ; b) The average uncertainty arisen from the connecting devices and settling of thermocouples; c) The average uncertainty arisen from the interaction of thermocouples with the systems. However, total uncertainties for each temperature measurement was calculated by using Equation (51), which is equal to $\pm 1.16 \%$. The total uncertainty in the pressure measurement was found to be $0.82 \%$. The total uncertainty associated with any function may be found by putting the values of the variables involved in calculating those functions in Equation (52) given above and then find out the relevant terms. The uncertainties associated with the COP, the exergy efficiency and the ratio of exergy loss to the capital cost for the whole the system was found to be $1.75 \%, 2.1 \%$, and $2.3 \%$, respectively.

The exergoeconomic analyses of the whole system and each component were performed using Equations (47) and (48). The ratio of exergy loss rate to the capital cost and the ratio of exergy loss rate to the capital cost values were found to be $12.8 * 10^{-4}$ and $7.92 * 10^{-4}$, respectively. It is clear from the results presented in Table 2 that the loss-to-capital-cost ratios based on energy for the components comprising the refrigerator and for the whole system is different than those based on exergy. This observation is in a good agreement with results obtained from the previous study for power plants by Rosen and Dincer[17] and for geothermal district heating systems by Ozgener et al.[22]. The value of the ratio of exergy loss rate to capital cost can vary for different technology, time, location, resource costs etc. For example, the values of " $\dot{R}_{e x}$ "may be different for different technologies. For any technology, it appears that the design of a device may be made more successful 
if it is modified, so that value of " $\dot{R}_{e x}$ " approaches appropriate. Therefore it is very crucial to obtain a balance between exergy loss and capital cost in real systems.

\section{CONCLUSION}

In this study, we have analyzed a refrigeration system with an internal heat exchanger and dual evaporator through energy, exergy, exergoeconomic techniques. The two evaporators were placed in two different chambers (freezer and cooler) to achieve different temperature values. The freezer chamber has a cooling load of $150 \mathrm{~W}$, while the cooler chamber is without any load. The system temperatures were fixed in the freezer and cooler at two different values (for the freezer chamber it was $-9.1{ }^{\circ} \mathrm{C}$ and for the cooler chamber $4.4{ }^{\circ} \mathrm{C}$ ) and were controlled. The efficiency for evaporator 1(one placed in the freezer chamber) varies between $89.47 \%$ to $93.54 \%$ while that for evaporator 2 (the one placed in the cooler chamber) is in the range of $81 \%$ to $92.22 \%$ on the net rational basis and product fuel basis, respectively. We have used the EXCEM method for the economic analysis.

We have listed some concluding remarks as follows:

a) The coefficient of cooling performance (COP) value for the system was determined to be 0.57 and it was concluded that the system had a very large irreversibility value.

b) The greatest irreversibility is due to the compressor with a relative irreversibility value of $76.29 \%$.

c) The energy and exergy loss rates were calculated to be $0.618 \mathrm{~kW}$ and $0.69 \mathrm{~kW}$, respectively.

d) The EXCEM parameters, $\dot{R}_{e n}$ and $\dot{R}_{e x}$ values, were also computed for each component and the overall system, with the values of $12.8 * 10^{-4}$ and $1.97 * 10^{-4}$, for the overall system, respectively.

e) The exergoeconomic optimization methods on refrigerators system with dual evaporators could contribute to determining the correct design of new equipment, especially by ensuring that value of " $\dot{R}_{e x}$ " for the equipment approaches an appropriate value of " $\dot{R}_{e x}$ ".

\section{Nomenclature}

$\dot{E}$

$\dot{E} X$

$\dot{L}$

K

h

S

$\dot{m}$

$\dot{Q}$

$\mathrm{k}$

$\mathrm{T}$

$\dot{W}$

RI

COP

$\dot{R}$

SI energy rate(kW)

exergy rate(kW)

thermodynamic loss rate $(\mathrm{kW})$

capital cost( in US\$)

specific enthalpy $\left(\mathrm{kJkg}^{-1}\right)$

specific entropy $\left(\mathrm{kJkg}^{-1}\right)$

mass flow rate $\left(\mathrm{kgs}^{-1}\right)$

heat transfer rate $(\mathrm{kW})$

heat transfer coefficient $\left(\mathrm{WK}^{-1}\right)$

Temperature(K)

Work rate or power $(\mathrm{kW})$

Relative irreversibility (-)

Coefficient of performance (-)

ratio of thermodynamic loss rate-to-capital cost $\left(\mathrm{kW} \mathrm{US \$}^{-1}\right)$

Sustainability index (-) 


\begin{tabular}{ll} 
IP & \multicolumn{1}{c}{ Improvement } \\
$\mathrm{u}$ & uncertainty \\
$\mathrm{R}$ & calculated result \\
$\mathrm{X}$ & variable \\
$\mathrm{P}$ & Pressure \\
$\mathrm{f}$ & function
\end{tabular}

\section{Greek letters}

$\psi$

specific exergy $\left(\mathrm{kJkg}^{-1}\right)$

$\mathcal{\varepsilon}$

exergy efficiency (\%)

$\eta$

energy efficiency $(\%)$

Indices

0

reference state

in

inlet

out

outlet

en

energy loss

ex

exergy loss

gen

generation

ac

accumulation

i

successive number

evap1

evaporator 1

evap 2

evaporator 2

$\mathrm{t}$

total

comp

compressor

mech, elect

mechanical and electrical

int

internal

cond

condenser

rec

receiver

H.E

heat exchanger

expan 1

expansion valve 1 


\section{ACKNOWLEDGMENT}

This study was supported by Vice Deanship for Scientific Research, College of Engineering, University of Dammam.

\section{REFRERNCES}

[1] M. Kanoglu, "Exergy analysis of the multistage cascade refrigeration cycle used for natural gas liquefaction," International Journal of Energy Research, vol. 26 pp. 763-774, 2002.

[2] A. Bejan, "Theory of heat transfer-irreversible refrigeration plants," International Journal of Heat Mass Transfer," vol. 32, pp. 16311639, 1989.

[3] G. Wall, "Optimization of refrigeration machinery," International Journal of Refrigeration, vol. 14, pp. 336-340, 1990.

[4] J. Chen, X. Chen, and C. Wu, "Optimization of the rate of exergy output of a multistage endoreversible combined refrigeration system," Exergy, vol. 1(2), pp. 100-106, 2001.

[5] K. Kaygusuz and T. Ayhan, "Exergy analysis of solar assisted heat pump systems for domestic heating," Energy, vol. 18 pp. 10771085, 1993.

[6] W. Leidenfrost, K.H. Lee, and K.H Korenic, "Conservation of energy estimated by second law analysis of power-consuming process," Energy, vol. 5, pp. 47-61, 1980.

[7] I. Dincer, "On energetic, exergetic and environmental aspects of drying systems, " International Journal of Energy Research, vol. 26(8), pp. 717-727, 2002.

[8] E. Torres-Reyes, D.E. Cervantes, and J. Gortari, "Optimal performance of an irreversible solar assisted heat pump," Exergy, vol. 1, pp. 107-111, 2001.

[9] H.C. Bayrakci, and A.E. Ozgur, "Energy and exergy analysis of vapor compression refrigeration system using pure hydrocarbon refrigerants," International Journal of Energy Research, vol. 33, pp. 1070-1075, 2009.

[10] A. Kabul, O. Kizilkan, and A.K. Yakut, "Performance and exergetic analysis of vapor compression refrigeration system with an internal heat exchanger using a hydrocarbon, isobutane (R600a)," International Journal of Energy Research, vol. 32, pp. 824-836, 2008 .

[11] M. Chandrasekharan, "Exergy Analysis of Vapor Compression Refrigeration System Using R12 and R134a as Refrigerants," Giap Journal, vol. 2, pp. 134-139, 2014.

[12] A. Stegou-Sagia, and N. Paignigiannis, "Exergy losses in refrigerating systems. A study for performance comparisons in compressor and condenser," International Journal of Energy Research, vol. 27 (12), pp. 1067-1078, 2003.

[13] G.K. Alexis, "Exergy analysis of ejector-refrigeration cycle using water as working fluid," International Journal of Energy Research, vol. 29(2), pp. 95-105, 2005.

[14] M.A. Rosen, "The relation between thermodynamic losses and capital costs for a modern coal-fired electrical generating station," In Computer-Aided Energy-Systems Analysis, Tsatsaronis G, Bajura RA, Kenney WF, Reistad GM, editors. AES-vol. 21, ASME: NY, pp. $69-78,1990$

[15] O. Ozgener, A. Hepbasli, and L. Ozgener, "A parametric study on the exergoeconomic assessment of a vertical ground coupled (geothermal) heat pump system, " Building and Environment, vol. 42(3), pp. 1503-1509, 2007.

[16] A. Hepbasli, Thermoeconomic analysis of household refrigerators, International Journal of Energy Research, vol. 31, pp. 947-959, 2007.

[17] M.A. Rosen, and I. Dincer, "Exergoeconomic analysis of power plants operating on various fuels," Applied Thermal Engineering, vol. 23, pp. 643-658, 2003.

[18] M.A. Rosen, I. Dincer, and M. Kanoglu, "Role of exergy in increasing efficiency and sustainability and reducing environmental impact," Energy Policy, vol. 36, pp. 128-137, 2008.

[19] W. Van Gool, "Energy policy: Fairly tales and factualities," Innovation and Technology-Strategies and Policies, Soares, O. D. D., Martins da Cruz, A., Costa Pereira, G., Soares, I. M. R. T., and Reis, A. J. P. S, editors. Dordrecht: Kluwer, pp. 93-105, 1997.

[20] J.P. Holman, "Experimental methods for engineers," $7^{\text {th }}$ Ed, New York: McGraw-Hill, pp. 48-143, 2001.

[21] H.W. Coleman, and W.G. Steele, "Experimentations and Uncertainty Analysis for Engineers, " 2 Ed., Wiley-Interscience, (1999).

[22] L.Ozgener, A. Hepbasli, and I. Dincer, "Thermodynamic analysis of a geothermal district heating system," International Journal of Exergy, vol. 2(3), pp. 231-245, 2005.

\section{AUTHOR PROFILE}

Muhammad Abid, working as a Lecturer at Universiy of Dammam Since 1st April 2013. He has completed his Master Degree in Mechanical Engineering from King Saud University (in Thermal and Fluids) under the supervision of Professor Arif Hepbasli. His research interest includes exergy analysis of hybrid systems. He completed his Bachelor Degree in Mechanical Engineering from University of Engineering and Technology Peshawar, Pakistan in 2009. He has experience in the research project for the desalination process using the concept of evaporation of water at low temperature in Mechanical Engineering Department of the King Saud University. He has completed several studies and research projects during his stay at University of Dammam. 
He is the first author of two Journal indexed with web of Science and one Journal indexed with Google Scholar. He has also three international conference publications.

A. Hepbasli was born in Izmir, Turkey on June 27, 1958. He received B.S. (first class honor) in mechanical engineering from Selcuk University (SU), Turkey in 1980, M.S. from Istanbul Technical University of Istanbul, Turkey in 1985 and a Ph.D. in mechanical engineering from Selcuk University in 1990 while he was working in industry. He joined Ege University in 1996 after about a ten-year period in industry at different positions and a one-year period at Izmir Branch Office of Chamber of Mechanical Engineers as a consultant. He has been appointed as the head of Energy Systems Engineering Department at Yaşar University in Izmir, Turkey since September 2012. He is the author and co-author of over 530 papers (over 250 SCI-based papers with an h-index of 34) on a national and international basis as well as several national and international books and book chapters. His research has been involved with energy, exergy, exergoeconomic and exergoenvironmental analyses and assessments of energy-related systems, energy/exergy efficiency and management, clean energy technologies, ground-source heat pumps, utilization and potential of renewable energy sources and sustainable energy technologies.

Khalid Saeed is working as a researcher in Mechanical Engineering Department, College of Engineering, King Saud University Riyadh, Saudi Arabia since $15^{\text {th }}$ December 2011. He is responsible for assisting the courses and teaching activities for Introduction to Engineering Drawing, Introduction to Engineering Design, Finite Element Method, Geometric Modelling in Engineering. He has recently completed his Master Degree in Mechanical Engineering from King Saud University, Riyadh, KSA. His research experience is related to bonded composite repairs in aircraft structures \& Renewable Energy. He has worked on several project related to Solar and Wind Energy and has made some research contribution. 